\title{
Research on China's Energy External Dependence and Energy Strategy
}

\author{
Yu Lulu ${ }^{1, a}$, Li Zhao ${ }^{2, b^{*}}$ \\ ${ }^{1}$ School of Economics and Management, Xi'an Mingde Institute of Technology, Xi'an, Shaanxi, China \\ ${ }^{2}$ School of Economics and Management, Xi'an Mingde Institute of Technology, Xi'an, Shaanxi, China
}

\begin{abstract}
After the reform and opening up, with the rapid development of economy and science and technology, high-tech products such as high-speed railway, train, aircraft, missile and rocket appear in response to the times. As people's living standards develop, they have a high consumption demand towards energy. For example, coal gas and natural gas take the place of firewood, and various new energy such as wind energy, tidal energy and solar energy emerge. China is now seeing a rapid industrialization. Although the amount of China's energy is large, the rigid demand of energy remains tense in supply and demand. Relatively speaking, China has a high energy external dependence, thus a series of measures were launched such as greatly advocating the implementation of new energy and reducing the exploitation quantity of coal properly. This paper will analyze the import and export data of various kinds of energy from 2015 to 2019 and calculate the external dependence level in 2019. After analyzing the current situation in China and consulting the national policies and information, the author will put forward suggestions on the current situation of China's energy.
\end{abstract}

\section{Background}

Energy is the most basic element for a country' sustainable development. The world had witnessed three energy revolutions, with each of which, the human civilization took a big step forward. Owing to the endowment, energy is not evenly distributed in every country. Besides, serving as the product of commodity economy, energy will cause troubles and disputes, worse still, it could lead to the turbulence in the international politics and economy. Because of the uneven distribution, energy issue has risen to the diplomatic, political, economic or even military level. As a matter of fact, though the energy issue had already existed, it did not reach its current height. After the two oil crises, energy security issues have gradually been paid attention to by people, countries or regions.

\section{Literature Review}

$\mathrm{Hu}$ Shuhan and others put forward relevant countermeasures and suggestions with the aim of avoiding the risk of US sanctions against Iran and ensuring the energy security. The purpose of his article is to propose measures on the possible negative and positive influence of China's energy security caused by the US sanctions against Iran.

Zhao Zhicheng and others used ARIMA model to predict China's short-term energy consumption and production, and they used Markov Chain to predict the change of China's energy consumption structure. Based on the development goals of the $13^{\text {th }}$ Five-Year Plan, they conducted an empirical study on the realization of China's energy strategic plan.

Guo Xiaotong constructed the STIRPAT model affecting China's energy consumption, which includes five indicators: total population, urbanization rate, consumption level of a family, industrial structure and energy intensity. They also conducted an in-depth study on the influencing factors of China's energy consumption in industrialization.

\section{Analysis on the Current Situation of China's Energy External Dependence}

\subsection{Analysis of China's Total Energy External Dependence}

Though China boasts of various kinds of energy, the coal dominates in energy constructure due to its endowment. China's energy consumption features more natural gas and less oil. In the early 1990s, China, with a low economic and technological level, was in self-sufficiency, and the demand of energy consumption is not as high as it is now, not to mention a minus degree of energy external dependence. After entering the $21^{\text {st }}$ century, the energy external dependence began to grow as the economic developed. In 2000, the external dependence of China was $5 \%$, and it rose to $18 \%$ in 2016 . In 2019 , the energy

\footnotetext{
a yull@mdit.edu.cn

*Corresponding author's e-mail: ${ }^{{ }^{*}}$ nwpulizhao@163.com
} 
external dependence of oil alone was as high as $70 \%$.

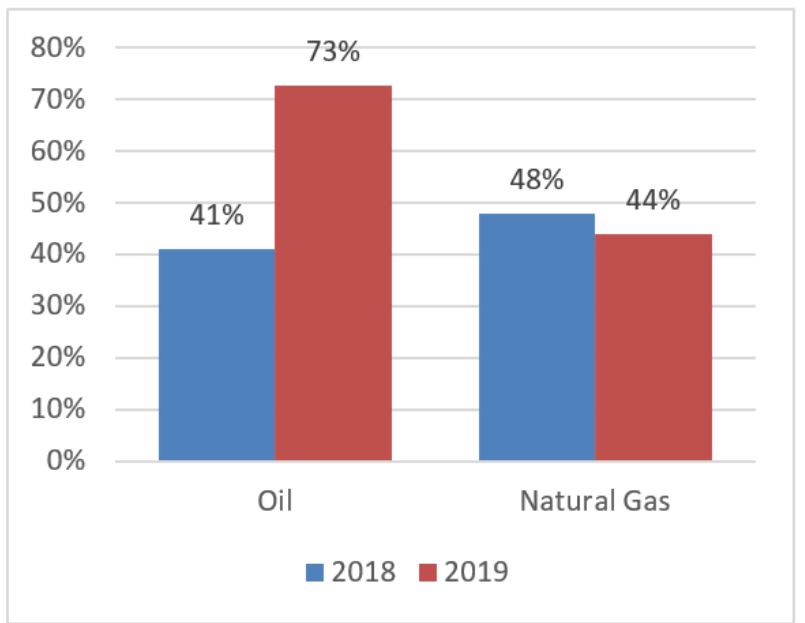

Figure 1: Comparison of External Dependence of Natural Gas and Oil from 2018 to 2019

\subsection{China's External Dependence on Oil}

Although China is the world's $6^{\text {th }}$ largest oil producer, it imports more oil than the United States and becomes the world's largest oil importer in 2018. In 2019, China's oil import reaches 500 million tons, up $9.6 \%$ year on year. From the figure below (Fig. 2), it's clear that China's crude oil production in 2019 is 191 million tons, $1 \%$ higher than that in the same period of 2018. It is the first growth since 2015 , and the consumption has also been growing, whose growth rate is relatively fast in 2018 . The export volume of oil has been decreasing while the import volume is increasing year by year. In 2019, China's oil export volume is about 810000 tons, and the import volume is 510 million tons.

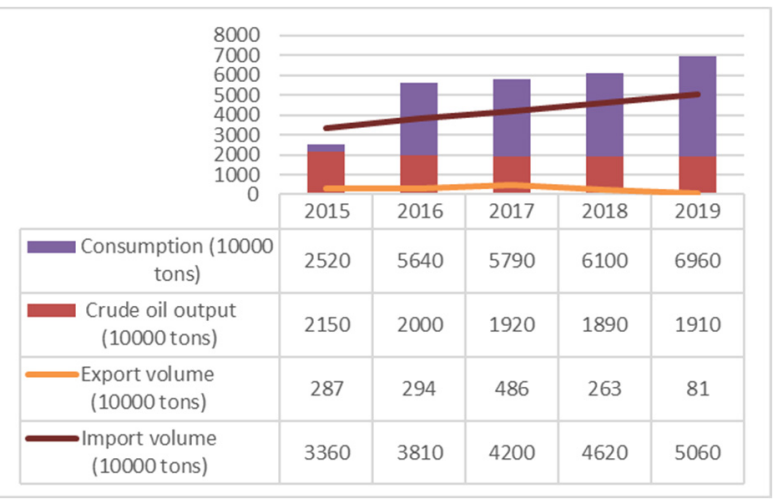

Figure 2: China's Oil Supply and Demand in 2015-2019 (unit: 10000 tons)

\subsection{China's External Dependence on Coal}

Coal reserves can be divided into three categories: possibly existed quantity, known quantity and recoverable quantity. According to the statistics of the $11^{\text {th }}$ World Energy Conference, the possible quantity of coal in the world is almost 13.6 trillion tons, among which the estimation of China is a slightly low with 1465 billion tons. The international community generally believes that China is rich in coal resources with the proven reserves ranked top in the world. China is the only country in the world where coal is the main energy source, while the coal resource is very limited. According to reports, China has discovered more than 200 billion tons of minable coal, and its reserve resources can reach 3 trillion tons. In 2019, the output of raw coal is 3.75 billion tons with a year-on-year increase of $4 \%$. The on-going structural reform of supplyside of the coal industry constantly released the production capacity of high-quality coal, promoted the steady growth of raw coal production in large-scale industries. From figure 3 , we can see that after reaching a highest point in July, the output growth rate has been declining.

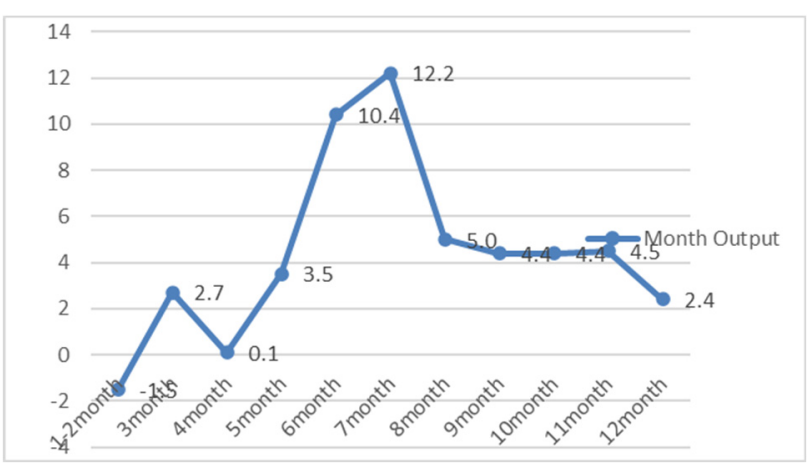

Figure 3: Growth Trend of Industrial Raw Coal Production Above Designated Size in 2019

Due to the decline in the growth rate of China's coal demand, China's coal export has been falling from 2014 to 2015, and it rebounded in 2016. In 2017, China imported 430 million tons of coal, an increase of $4 \%$ over 2016 , and the import volume was 39.4 billion US dollars with an increase of $61 \%$ over 2016. In 2018, China's total primary energy output was 3.8 billion tons of standard coal, up 5\% over 2017. China used to be a major coal exporter, but owing to the rapid growth of domestic coal consumption in recent years, China has changed from the most important coal exporter to a net coal importer. Comparing the coal import and export figure in 2018 and 2019 (figure 4), the import volume in 2019 is nearly 30 million tons more than that in 2018. As for import, China's coal sources are relatively concentrated in countries such as Australia, Indonesia and Russia. Although China has a huge coal import, on the whole, China's external dependence on coal energy is relatively balanced.

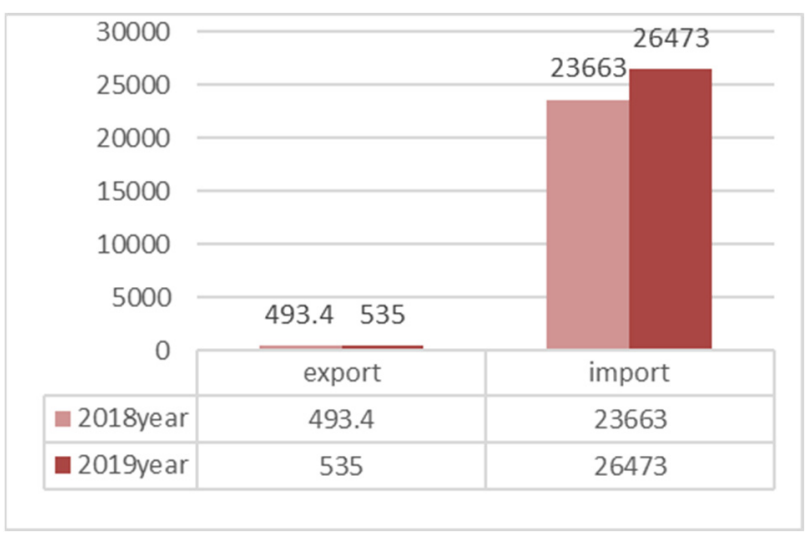

Figure 4: China's Coal Import and Export from 2018 to 2019 (unit: 10000 tons) 


\subsection{China's External Dependence on Natural Gas}

In 2013, China initiated a large-scale wave of "changing coal to gas" for the first time. In 2017, with the introduction of various new environmental protection policies, the campaign of "changing coal to gas" was highly praised in intensive, residential, commercial, public service and industrial fields. As for the energy, the growth of natural gas demand reached $15.3 \%$ in the same year, and then rose to $45 \%$ in the second year. After the corresponding policy adjustment in 2019, the growth began to slow down. Moreover, the widely distributed natural gas pipeline network of China means that the demand of China's natural gas will continue to rise. Therefore, although China's natural gas production has been growing slowly, the growth rate of production is far behind that of consumption, and the gap between supply and demand of natural gas is gradually widening. At the beginning of 2018, "natural gas shortage" appeared in China when the price of natural gas was in a rapid increase. By 2019, although the total supply of natural gas is 313 billion cubic meters, far greater than the demand of 299 billion cubic meters, China is still in a balanced "tense state " in 2019 due to its limited supply.

natural Gas Production (100 million cubic meters)

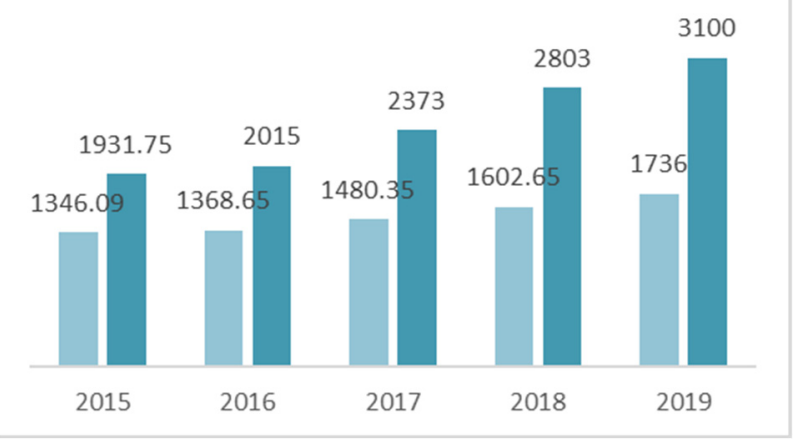

Figure 5: China's Natural Gas Import and Export from 2015 to 2019 (unit: 100 million cubic meters)

\section{Analysis of the Impact on Economic Development of China's High Energy External Dependence}

The status of energy is becoming increasingly special and significant. However, in recent years, China's total energy imports continue to increase, and the high energy dependence makes a negative impact on China's economic development to a certain extent.

\subsection{The rising cost of energy import affects economic security}

First of all, the high energy external dependence will restrict our access to energy resources. At present, China mainly imports oil come from the Middle East, Africa and Southeast Asia through the Indian Ocean, the Strait of Hormuz and the Strait of Malacca, where the piracy is rampant and the warships of India, who had reached a military agreement with Singapore, stationed in order to monitor China's oil tankers, which means that our every move is under their surveillance. Then, once the international situation has undergone major changes, we will inevitably be held back and manipulated by the unpredictable impacts and influences. Worse still, the turbulence happened in international or domestic area will put us in a very passive position. China's energy import cost and procurement will increase, leading to a rise in the domestic prices and a panic among the people. Any turbulence in the community society will directly affect economic security.

\subsection{Imbalance and deficit in Balance of Payments}

Under the economic globalization, the energy security of a country is not only about ensuring the balance of domestic energy supply. Due to the internationalization of energy market brought by economic globalization, the solution to the contradiction between domestic energy supply and demand relies on energy import. A stable development of national economy is closely related to the its energy external dependence. Moreover, for those combat preparedness resources with high import, the international political turbulence or the instability of the energy and raw materials in international market will serve as the bottleneck to directly affect China's economy. In the meanwhile, it is likely to influence the price of raw materials in the international market and lead to inflation eventually.

\section{Suggestions on the Energy Development in China}

\subsection{Interregional energy allocation}

The regional distribution of China's energy resources is extensive and relatively concentrated, especially for natural gas and oil, whose distribution are very uneven. For example, $64 \%$ of China's proven minable coal is concentrated in Northern China, and $50 \%$ of China's proven minable oil is in Northeast China. Most of China's coal and oil resources are concentrated in the north of China, while water resources are concentrated in the southwest. Therefore, in order to solve this dilemma, China has to carry out several energy projects such as West to East Gas Pipeline, North to South Coal Transmission, West to East Power Transmission, North to South Oil Transmission and South to North Water Diversion Projects, aiming to fundamentally solve the problem of uneven energy distribution in China and realize the optimal allocation of resources through complementing each other's advantages, sharing resources and adjusting measures to local conditions. By combining the advantages of resources in the West with the economic and technological advantages in the East, we can further improve the utilization rate of resources, reduce the import of energy, and reduce the high degree of energy external dependence. 


\subsection{Promote a sustainable and green development of energy with technology innovation}

With the rapid growth of China's economy and the further acceleration of industrialization, the sustained growth of energy consumption has brought a series of environmental problems to our country. Therefore, concepts of energy conservation and emission reduction have been proposed and advocated, which has gradually become the most fundamental and effective way to solve China's energy and environmental problems. The technology innovation in energy plays a very important role in energy conservation and emission reduction, through which, it vigorously promotes the development and application of new energy and renewable energy technology, which is conducive to alleviate the sharp contradiction between economic growth and resources and environment. Only when new energy and renewable energy are used widespread can our country's demand for primary energy be alleviated and the high degree of external dependence be reduced. Therefore, technology innovation is supposed to use to effectively promote a sustainable development of energy.

\subsection{Increase overseas energy investment in Southeast Asian countries and other developing countries}

China is supposed to conduct strategic resource reserve by increasing the development investment in overseas natural resources, in particular, the foreign investment with resource-based. At present, resources are mainly distributed in developing countries, thus, to maintain a more stable resources supply, China should strengthen economic assistance and strategic investment to developing countries.

\section{Conclusion}

Energy is the basic motive force of a country's social development, which is closely related to society, economy, politics and military. It is the source of power for various industries and the basis for the normal conduct of all production activities.

According to all kinds of data, China's external dependence on energy is generally relatively high relatively high, judging whether a country's external dependence is high or not is $50 \%$, while China's external dependence on oil, gas and coal basically exceeds this security line. Moreover, in recent years, China's international status has gradually increased, the energy import route is relatively single, and the transit is also dangerous, which poses a great threat to China's energy, economic and social security. Therefore, our government has also taken more measures to reduce the threat coefficient: built four oil import lines, strengthened the strategic reserve of energy, strengthened the development and utilization of new energy, and so on.

\section{Acknowledgments}

Project: Research on Teaching Reform of Business Negotiation Course Based on Actual Projects, No. 85 of the College (2019), 2019 Education and Teaching Reform Research Project of Mingde College of Northwestern Polytechnic University

\section{References}

1. Li Xinlei, Yao Shifan, Su Jianjun. Qinghai Social Sciences. One belt, one road, sustainable energy security strategy choice: supply side analysis of public products based on the China Central Asia Energy Internet Construction [J]. 2018 (04).

2. Yuan Yi, Shu Zhan. Comparison and Enlightenment of energy security between China and the United States [J]. Sino-Global Energy, 2019,24 (02).

3. Zhao Zhicheng, Liu Qunyi. Research on China's energy strategic planning -- the prediction based on energy consumption, energy production and energy structure [J]. Resources and Industries, 2019,21 (06).

4. Guo Xiaotong. Research on the influencing factors of energy consumption during China's industrialization [D]. Harbin Institute of Technology 